\title{
OPTIMALISASI WAKAF MARKET MELALUI PENGEMBANGAN GO WAKAF (STUDI PADA MINIMARKET “AL-KHAIBAR” MALANG)
}

\author{
Oleh :Egi Agutian R.S, Hayyu Afuw,Yulinda Nordiana M.A.S \\ Jurusan Perbankan Syariah S1, Fakultas Ekonomi UIN Maulana Malik Ibrahim Malang
}

\begin{abstract}
Muslims in Indonesia are the most major element. With a population of 254.9 million, Indonesia is the country with the largest number of Muslims in the world. Based on data from the Central Bureau of Statistics 2015, the number of Muslims in Indonesia is about $87 \%$. But not optimally run the function of the mosque as a central activity of Muslims both in mahdhah worship and ghair mahdhah. In order to realize the function, the potential development of Islamic philanthropy in the mosque becomes the right choice one of them is the development of productive waqf in the form of wakaf market.

Wakaf market Al-Khaibar Malang is an access for people to simplify the system of sale and purchase based on the mosque. However, market managed wakaf needs to adjust the current state of digital-based. Therefore, Al-Khaibar market wakaf need to develop vehicle waqf to be the target market expansion. The purpose of this research is Knowing Capital and Development of productive waqf mini market AlKhaibar and provide innovative development of productive waqf mini market Al-Khaibar.

The type of research used in this study is empirical research (field research). data collection methods that researchers use is by interview and documentation and secondary data that other litelatur relevant to the research material. Data analysis method used in this research is descriptive analysis.

The results obtained, Minimarket Al-Khaibar has a policy of implementation of productive endowments include the percentage of installment repayment minimal mini capital to be returned and allocation of funds productive endowments. Nadzir reward is intensive alaih. The minimarket manager consists of managers and employees. Employment recruitment is preferred from surrounding communities and people in need of employment, prospective workers register with application letter, following interview selection by manager. Also establishing partners with distributors like Unilever and the location of minimarkets adjacent to the mosque is very strategic in the development effort Go Wakaf. So that the mosque is really central to the activities of Muslims, especially in the field of independent economy.
\end{abstract}

Key Word :Optimizing wakaf ptoduktif, Wakaf market, Go Wakaf

\section{PENDAHULUAN}

Agama Islam di Indonesia adalah agama mayoritas yang dianut oleh warga negaranya. Dengan jumlah penduduk 254,9 juta, Indonesia adalah negara dengan jumlah muslim terbesar di dunia. Berdasarkan data Badan Pusat Statistik (BPS) tahun 2015, jumlah umat Islam di Indonesia sekitar 87\% dari populasi (Badan Pusat Statistik, 2015). Pertanyaannya seberapa pengaruh kemayoritasan kaum muslimin Indonesia itu terhadap perkembangan Indonesia, dapat dijawab dengan mulai berkembangnya ekonomi Islam di Tanah Air.Wakaf adalah salah satu dari syari'at Islam sebagai bentuk ibadah kepada Allah yang juga dapat berfungsi di bidang sosial. Oleh karenanya, wakaf sebagai suatu sarana yang dapat dipergunakan bagi seorang muslim untuk mewujudkan dan memelihara hubungan manusia dengan Allah SWT serta hubungan manusia dengan manusia lain dalam masyarakat.

Dilihat dari sumber daya alam atau tanahnya jumlah harta wakaf di Indonesia mencapai 435 ribu persil dengan luas sekitar 436 ribu hektare, yang jika diuangkan nilainya bisa lebih dari Rp. 200 triliun (www.bwi.or.id, 2017). Menurut data Depertemen Agama terakhir terdapat kekayaan tanah wakaf di Indonesia sebanyak 403.845 lokasi dengan luas 1.566.672.402 M2. Dari total jumlah tersebut $75 \%$ diantaranya sudah bersertifikat wakaf dan sekitar $10 \%$ memiliki potensi ekonomi tinggi, dan masih banyak lagi yang belum terdata (Direktorat Pemberdayaan Wakaf, 2007 : 37) merupakan jumlah harta wakaf terbesar di seluruh dunia.Setelah Undang- Undang Wakaf Tahun 2004 yang berkaitan dengan wakaf tunai atau uang disahkan, jumlah uang yang diperoleh mencapai Rp 120 triliun per tahun jika 100 juta rakyat Negara Indonesia berwakaf Rp 100 ribu per bulan (tabel.1.1) (Majjiburrahman, 2015).Ini merupakan tantangan bagi umat Islam Indonesia untuk mengfungsikan harta wakaf tersebut secara 
maksimal sehingga tanah-tanah tersebut mampu mensejahterakan umat Islam di Indonesia sesuai dengan fungsi dan tujuan ajaran wakaf yang sebenarnya (Zuliansyah, 2014).

Di Indonesia Undang-Undangtentang pengelolaan harta wakaf diatur dalamNomor 41 Tahun 2004 ayat (42): "Nazhir wajib mengelola danmengembangkan harta benda wakaf sesuai dengan tujuan, fungsi, dan peruntukannya". Dari ayat tersebut pemerintah berharap agar paranadzirdapatmengelola harta wakaf yang tadinya pemanfaatan harta wakaf sebagai konsumtif dapat menjadi produktif. Salah satu hal yang selama ini menjadi hambatan riil dalam pengembangan wakaf agar lebih produktif di Indonesia adalah keberadaan nadzir (pengelola) wakaf yang masih tradisional. Ketradisionalan nadzir dipengaruhi, diantaranya: Karena masih kuatnya paham mayoritas umat Islam yang masih stagnan (beku) terhadap persoalan wakaf, rendahnya kualitas Sumber Daya Manusia (SDM)nadzir wakaf, lemahnya kemauan para nadzir wakaf juga menambah ruwetnyakondisi wakaf di tanah air (Djunaidi dan Asyhar, 2007).

Pernyataan diatas menunjukkan bahwa dalam praktiknya, penerapan wakaf produktif memiliki kendala salah satunya di bidang Sumber Daya Manusia (SDM). Akhirnya, pemanfaatan harta benda wakaf masih banyak digunakan untuk kepentingan ibadah seperti masjid, musholla, pesantren, kuburan, dll. Jika nadzir memiliki kemampuan dan kemauan untuk mengubah paham tradisionalnya, maka inovasi-inovasi dalam pengembangan wakaf agar lebih produktif akan terus bermunculan. Sehingga hasil dari wakaf produktif tersebut dapat dioptimalkan oleh masyarakat luas.

Minimarket "Al-Khaibar" merupakan minimarket yang dibangun menggunakan harta benda wakaf berupa tanah dan uang. Minimarket tersebut menjadi inovasi dan proyek percontohan wakaf produktif di Indonesia dan menjadi minimarket pertama yang ada di Indonesia. Oleh karenanya, minimarket tersebut dapat digunakan sebagai bahan edukasi dalam pengelolaan wakaf produktif yang modern. Disamping itu, guna menyesuaikan zaman modern ini yang serba digital, model wakaf produktif berupa minimarket tersebut masih perlu adanya pengembangan teknologi (penambahan model wakaf) berupa Go Wakaf.

Tujuan dilakukannya penelitian ke Minimarket "Al-Khaibar" yaitu untuk mengetahui latar belakang penerapan wakaf produktif melalui minimarket, mengetahui pengelolaan dan cara kerja minimarket, serta pengembangan model produk dan manfaat minimarket untuk masyarakat sekitar.

\section{Metode Penelitian}

Jenis penelitian yang digunakan adalah penelitian studi literatur dengan mencari referensi teori yang relevan dengan kasus atau permasalahan yang ditemukan. Referensi teori yang diperoleh dengan jalan penelitian studi literatur dijadikan sebagai pondasi dasar dan alat utama bagi praktek penulisan di lapangan.

Pendekatan penelitian yang digunakan adalah penelitian kualitatif. Penelitian kualitatif adalah penelitian yang menghasilkan dan mengolah data yang sifatnya deskriptif, seperti transkripsi wawancara, catatan lapangan, gambar, foto rekaman video dan lain-lain. Dalam penelitian kualitatif perlu ditekankan pada pentingnya kedekatan dengan orang-orang dan situasi penelitian, agar penulis memperoleh pemahaman jelas tentang realitas dan kondisi kehidupan nyata.

Selain itu penulis juga menggunakan pendekatan Konseptual (conceptualapproach) (Peter, 2005) untuk memperoleh kejelasan dan pembenaran ilmiahmengenai pengoptimalan wakaf. Adapun jenis data yang digunakan penulispada penelitian ini adalah data primer (data langsung) dan data sekunder (data dari sumber yang sudah ada berupa dokumentasi atau data - data yang dianggap penting melalui artikel, jurnal dan media lainnya). Juga, dalam melakukan Analisa data penulis menggunakan Teknik deskriftif kualitatif yang meliputi beberapa tahap, yaitu mengorganisasikan data, pengelompokan berdasarkan kategori, menguji asumsi atau Permasalahan yang ada terhadap data, mencari alternatif penjelasan bagi data dan menulis hasil penelitian.

\section{HASIL DAN PEMBAHASAN}

\section{Profil Minimarket Al-Khaibar}

Minimarket “Al-Khaibar"diresmikanolehDirjenBimas Islam Kementrian Agama RI Prof. Dr. H, Machasin., MA, padatanggal 11 Juni 2015 M/24 Sya'ban 1436 H, yang manapengembangantanahwakaf berawal dari wakaf ruang rawat inap VIP Universitas Islam Malang (UNISMA).

Nama "Al-Khaibar" diambil dari nama tanah wakaf pertama kali yaitu tanah "Al-Khaibar" yang dilakukan oleh Umar bin Khattab. Tanah ini sangat disukaioleh Umar karena subur dan banyak hasilnya. 
Namun demikian, beliau meminta nasehat kepada Rasulullah tentang apa yang seharusnya diperbuat terhadap tanah itu. Maka Rasulullah menyuruh agar Umar menahan pokoknya dan memberikan hasilnya kepada para fakir miskin, dan Umar pun melakukannya. Substansi perintah Nabi tersebut adalah menekankan pentingnya eksistensi benda wakaf dan mengelolanya secara profesional. Sedangkan hasilnya dipergunakan untuk kepentingan kebajikan umum (Djunaidi dan Asyhar, 2007).

Modal awal pembangunan minimarket yaitu berupa wakaf tanah milik LPP Ma'arif dan berupa wakaf uang sejumlah Rp 2 Milyar dari Kementerian Agama. Dari nominal tersebuttidak semuanya dihabiskan, digunakan hanya Rp 1,2 M untuk pembangunan gedung beserta isi minimarket. Minimarket "Al-Khaibar" ini merupakan lembaga murni profit. Dalam pengelolaan wakafnya diserahkan kepada nadzir dimana dalam lembaga ini ketua nadzirnya adalah Bapak Zawawi Muhtar. Sedangkan untuk pengelolaan minimarket diserahkan kepada pengelola minimarket yang terdiri dari manajer, kasir dan karyawan.

Minimarket “Al-Khaibar"didirikan untuk mensejahterakan ekonomi umat. Struktur dalam lembaga ini meliputi nadzir yang bertugas sebagai komisaris, serta memiliki kebijakan pelaksanaan wakaf produktif meliputi prosentase cicilan pengembalian modal awal minimarket yang harus dikembalikan dan alokasi dan ahasil wakaf produktif. Seorang nadzir mendapatkan upah yang dinamakan dengan intense falaih. Nadzir sebagai pihak yang bertugas untuk memelihara dan mengurusi wakaf mempunyai kedudukan yang penting dalam perwakafan. Sedemikian pentingnya kedudukan nadzir dalam perwakafan, sehingga berfungsi tidaknya benda wakaf tergantung dari nadzir sendiri. Untuk itu, sebagai instrument penting dalam perwakafan, nadzir harus memenuhi syarat-syarat yang memungkinkan, agar wakaf bisa diberdayakan sebagaimana mestinya (Djunaidi dan Asyhar,2007).

Pengelola minimarket terdiri dari manajer, kasir dan karyawan. Dalam perekrutan tenaga kerja diutamakan dari masyarakat sekitar dan orang-orang yang membutuhkan pekerjaan. Calon pekerja mendaftar dengan membawa surat lamaran kemudian mengikuti seleksi wawancara oleh manajer.

Dalamhal pemasokan barang, minimarket "Al-Khaibar"mendapatkan pasokan barang dari para distributorsepertidari Unilever dan PT Indomarco. Barang yang dijualmeliputi makanan pokok, makanan ringan, minuman, peralatanmandi, dan kebutuhan rumah tangga lainnya.Rata-rata nilai transaksi (omzet) yang dicapai Rp 300 juta, kemudiandari hasil pendapatan tersebut $70 \%$ digunakan untuk pengembalian modal awal dan 30\% untuk insentif, pangsapasar yang ditujuadalah para mahasiswakhususnyamahasiswa UNISMA (Universitas Islam Malang).

Adapunkelebihandankekurangandari minimarket "Al-Khaibar", kelebihannyameliputi:Pertama, harga yang ditawarkan lebih kompetitif dibanding pesaing karena minimarket tidak perlu membayar royalty kepada pihak lain. Kedua, selain profit oriented minimarket juga mengadakankegiatan sosialdisekitar minimarket seperti memberikan santunankepadakaumduafa, memberikankas rutin kepada RT, memberi insentif kepada khotib dan imam tetap masjid Ainul Yaqin. Ketiga, memiliki cabang di daerah Ketawanggede (Minimarket “Al-Khaibar”'II) dan masih dalam proses pembangunan (Minimarket “Al-Khaibar"III) di dekat masjid Sabilillah, Singosari. Selain itu minimarket ini telah melakukan pembelian Franchise "Go Fish and Chicken" disebelah minimarket "Al-Khaibar'I sebagai pengembangan usaha di bidang kuliner. Dalampembagian bonus (fee)Go Fish and Chicken yaitu35\% untuk pengelola,55\% untuk wakaf produktif, dan $10 \%$ digunakan untuk infaq. Kemudiankekurangannyayaitu belum mendapat pasokan langsung dari pabrik karena masih sedikitnya jumlahcabang. Dan kekurangannya diantaranya: pertama, belum memiliki Gudang besar sehingga belum mampu menyediakanpersedian dengan volume yang besar. Kedua, dalam memasarkan produk berbasis online masih menggunakan sistem milik unilever. Ketiga, persedian barang masih bekerjasama dengan corporate, belum menyentuh secara optimal UMKM Masyarakat bawah yang memiliki kendala dalam aspek pemasarannya. Respon masyarakat sekitar minimarket "Al-Khaibar"sangat positif terhadapadanya minimarket ini, karena letak minimarket yang strategis dekat dengan kampus dan pemukimanwarga, selain itu karenalengkapnyabarang yang diperdagangkandapat memenuhi kebutuhan masyarakat.

Dalam usahanya ini minimarket "Al-Khaibar"memiliki rencana dalam pengembangan dengan menambah jumlah cabangdan membangun Depo (gudang besar) sehingga bisa menjadi supplier bagi minimarket dan toko lain, sehingga minimarket tidak perlu lagimen-supply barang dari luar. Metode yang akan digunakan dalam pengembangan minimarket adalah metode pengembangan dana wakaf dan dana dari investor.

Minimarket ini berkembang cepat dan mendapat respon positif dari masyarakat sekitar. Selain menyediakan kebutuhan masyarakat dengan harga murah, minimarket juga dapat membuka lapangan 
kerja, serta ikut andil dalam kegiatan sosial disekitar minimarket. Dengan adanya pemanfaatan wakaf produktif berupa minimarket, dapat menjadi alternative penyaluran wakaf produktif untuk mensejahterakan masyarakat sekitar. Sehingga hasil dari pengelolaan wakaf tersebut dapat dinikmati secara optimal.

\section{Permodelan Wakaf Market "Al-Khaibar" Sekarang}

Dari hasil penelitian di Minimarket "Al-Khaibar" diketahui bahwa minimarket " $A l$ Khaibar" merupakansalah satu contoh pemanfaatan wakaf produktif berbasis minimarket di Indonesia. Dalam pengelolaan minimarket sumber pendanaanya berasal dari pengembangan wakaf rumah sakit UNISMA ruang VVIP. Pengelolaan minimarket ini melibatkan nadzir, manajer, dan produsen.

\section{Bagan1.1 Pengelolaan dan Penyaluran Hasil Wakaf Market"Al-Khaibar}

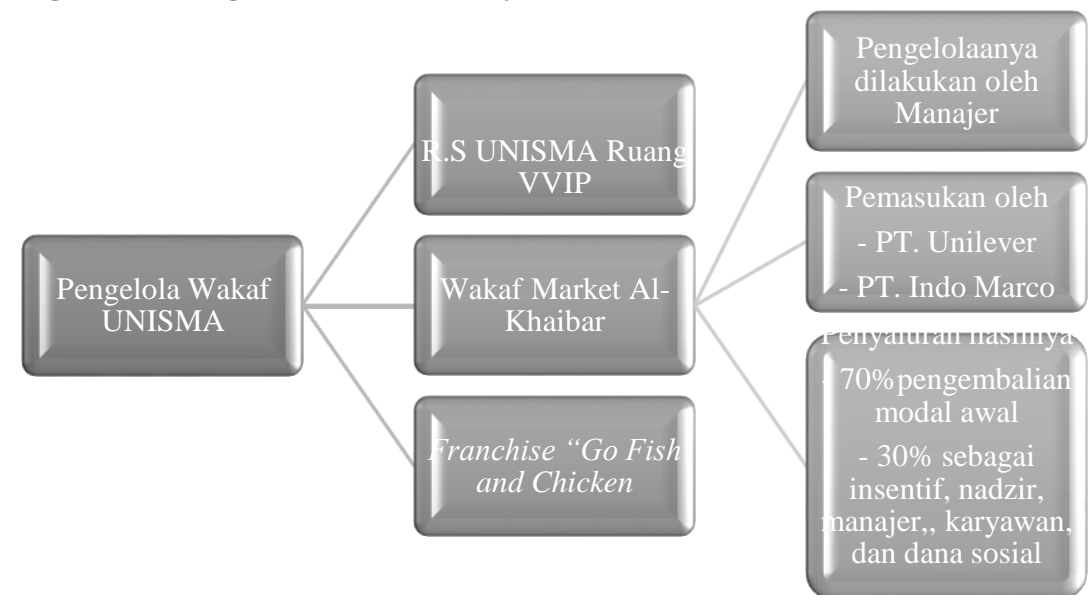

Bagan 1.2 Model Pengembangan Go Wakaf

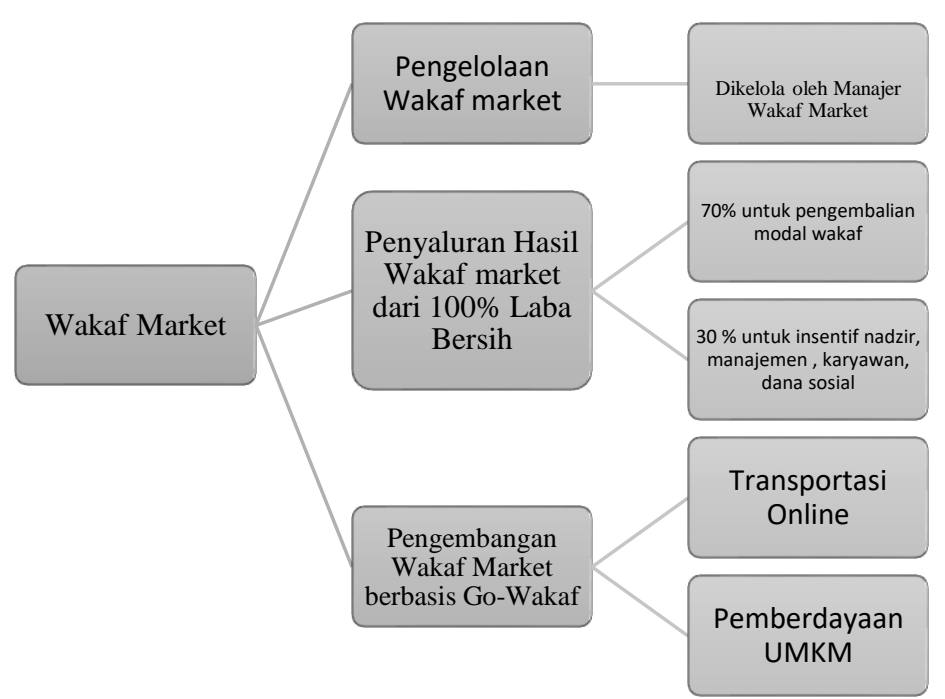

Pengelolaan dan penyaluran wakaf market mini market "Al-Khaibar", pengelolaannya diserahkan sepenuhnya kepada manajer wakaf market "Al-Khaibar"tentunya tetap dalam pengawasan nadzir juga. Untuk penyaluran hasilwakaf market "Al-Khaibar" dibagi menjadi dua bagian yaitu $70 \%$ digunakan untuk menyicil pendanaan dari wakaf, 30 persen digunakan sebagai intensif para nadzir, karyawan dan untuk pendanaan sosial, mengapa perlu melakukanpendanan sosial karena tidak terlepas dari fungsi wakaf yaitu mensejahterakan umat.

Dari gambaran di atas terlihat optimalisasi wakaf produktif dengan model wakaf market ini sangat berpotensi baik dalam hal profit maupun sosial, namun belum memberikan wadah dalam 
membina masyarakat lebih mandiri dalam aspek ekonomi. Agar minimarket dapat lebih berkembang, mensejahterakan masyarakat menengah ke bawah dan dapat bersaing unggul dengan minimarket lainnya, perlu adanya digitalisasi dalam dengan melakukan aplikasi Go Wakaf. Dari hasil wawancara dengan manajer yang penulis lakukan dengan manajer "Al-Khaibar" bahwasanya minimarket "Al-Khaibar" dalam memberikan fasilitas pembelian online masih menggunakan start upmilik unilever termasuk dalam membeli persedian barangnya. dikarenakan belum memiliki start up milik sendiri dan belum memiliki Gudang besar. Oleh karenanya penulis membuat konsep Go Wakaf guna memberikan kemudahan dalam mengakses transaksi, mengembangkan produk UMKM Masyarakat menengah ke bawah. Pengembangan model wakaf produktif yaitu berbasis Go Wakaf.

Go Wakaf merupakan model wakaf produktif dengan memanfaatkan wakaf kendaraan atau pembelian kendaraan dari wakaf tunai untuk dijadikan transportasi online yang memiliki dua fungsi yaitu delivery order untuk membantu proses transaksi jual beli di wakaf market tersebutdan memberikan jasa ojek online. Disamping itu Go Wakaf juga mencoba mengajak UMKM untuk memmasok produknya ke Minimarket tersebut, yang kemudian minimarket "Al-Khaibar" menjual produk UMKM juga. Dengan menggunakan model Go Wakaf mini market "Al- Khaibar", pendayagunaan wakaf market terrealisasikan secara optimal dan dapat mengikuti perkembangan zaman yang sudah serba digital. Adapun model Go Wakaf ini memiliki beberapa fungsi meliputi:

1. transaksi jual beli secara online

2. memasarkan produk corporate dan UMKM

3. controlling produk UMKM

4. Jasa transportasi online

5.

\section{Pemodelan dan Perancangan Go Wakaf}

\section{- Pemodelan}

Go Wakaf dikembangkan dengan pendekatan mendesain model, aktivitas atau proses- proses untuk merekayasa perangkat lunak berdasarkan sifat aplikasi, beserta alat- alat bantu yang dipakai.

Aplikasi Go Wakaf yang akan di modelkan seperti gambar di bawah ini.

- Perancangan

Perancangan aplikasi Go Wakaf menggunakan platform client-server dan menggunakan web browser sebagai media antarmukanya. Pemodelan arsitektur aplikasi dan pengguna aplikasi dapat diidentifikasi.

- Use Case Diagram

Aktivitas atau proses-proses berdasarkan sifat aplikasi digunakan sebagai alat bantu perancangan model fungsi use case diagram. Use case diagram sebagai rangkaian yang membentuk sistem dalam sebuah model secara teratur yang dilakukan oleh aktor dan direalisasikan melalui sebuah

collaboration (Presman. R.S., 2001)

\section{Implementasi Rancangan Aplikasi Go Wakaf}

Setelah dilakukan pemodelan dan perancangan sistem, maka tahap selanjutnya adalah mengkonversi fungsi- fungsi ke dalam pemerograman. Pada tahapan ini juga sekaligus dilakukan pengujian dan evaluasi sistem. Pada tahap pengujian akan ditampilkan semua proses mulai dari masukan data, pemerosesan informasi sampai dengan menghasilkan bentuk berupa laporan, dokumen (macam- macam produk), dan keluaran lainnya yang relevan.

Home/ Beranda

Login (Masukan no handphone dan password)

Pemesanan

1. Penawaran Menu

2. Delivery Order

$>$ Mini Market

$>$ Go Fish and Chicken

$>$ Saham Tunai

$>$ Wakaf

1. Rp $10.000,00$

2. $\operatorname{Rp} 20.000,00$

3. $\mathrm{Rp} 50.000,00$

4. $\operatorname{Rp} 100.000,00$ 
Shadaqah / Infaq

1. Rp $10.000,00$

2. $\mathrm{Rp} 20.000,00$

3. $\mathrm{Rp} 50.000,00$

4. $\operatorname{Rp} 100.000,00$

Go - Ride
1. Tujuan
2. Lokasi Anda
3. Order Go- Ride
4. Harga
$\begin{array}{ll}\checkmark & 0 \mathrm{~km}-2 \mathrm{~km}: 4000 \\ \checkmark & 2,1 \mathrm{~km}-3 \mathrm{~km}: 5000 \\ \checkmark & 3,1 \mathrm{~km}-4 \mathrm{~km}: 6000\end{array}$

Ket : Setiap ketambahan $1 \mathrm{~km}$ harga akan ditambahkan sebesar Rp 1.000,00

\section{KESIMPULAN}

Rancang bangun aplikasi Go Wakaf dimulai dari analisis, perancangan dan implementasi sistem. Hasil pengembangan sistem aplikasi diharapkan dapat digunakan untuk mengelola (menghimpun, menyimpan, memproses), mengontrol dan memediasi transaksi (Jual beli dan Ojek Online) serta menghasilkan informasi produk- produk yang tersedia (Corporate dan UMKM), Controlling UMKM binaan dan keluaran lainnya yang relevan.

Selanjutnya pada tahap implementasi diharapkan pengelolaan dan pengendalian wakaf market khususnya dalam aspek marketing pada masa yang akan datang dapat bersaing unggul dengan para pesaingnya. Disamping itu, wakaf market ini dapat membantu, mebina, mengontrol UMKM Mitra/ binaan secara massif, sehingga dengan adanya Go Wakaf ini diharapkan mampu meningkatkanprofit wakaf market juga menumbuhkan keuntungan dan inovasi pada UMKM mitra/binaan.

\section{DAFTAR PUSTAKA}

Djunaidi dan Asyhar. "Menuju Era Wakaf Produktif".

Depok:MumtazPublishing. 2007

Badan Wakaf Indonesia. 2017. http://bwi.or.id. Diakses pada /2017 pukul 23.45 WIB

Direktorat Pemberdayaan Wakaf. 2007. "Panduan Pemberdayaan Tanah Wakaf Produktif Strategis di Indonesia". Jakarta

Djunaidi, Achmad dan Thobieb Al-Asyhar. 2007. Menuju Era Wakaf Produktif. Depok: Mumtaz Publishing

Fahmi Amiq, dkk. Aplikasi Sistem Informasi Geografis Manajemen Aset Wakaf. 2015

Majjiburrahman. Wakaf di Indonesia. 2015.

Nugroho, Adi, dkk. Aplikasi SistemInformasi Geografis E- wakaf Sebagai Tool Pengelolaan Aset Wakaf Pada Kantor Kementerian Agama Kota Surakarta. 2013

Rozalinda. 2015. Manajemen Wakaf Produktif. Jakarta: Rajawali Press

Sugiyono, 2014 “metode penelitian kuantitatif Kualitatif dan R\&D”, Alfabeta. Bandung.

Syaikh Muhammad bin Shalih al-'Utsaimin. 2008. Panduan Wakaf, Hibah dan Wasiat Menurut AlQuran dan Sunnah. Jakarta: Pustaka Imam Asy-syafi'i 